\title{
Study and Reflection on the Optimized Allocation of Papery and Electronic Resources in University and College Libraries
}

\author{
Fanzi $\mathrm{Li}^{1,{ }^{*}}$, Zhuoyi $\mathrm{Xu}^{1}$, Fangyuan $\mathrm{Han}^{1}$ \\ ${ }^{1}$ Department of Mathematics, Southeast University, Nanjing 210096, China \\ *franceleelfz@gmail.com
}

Keywords: "Two-in-One" system, digital object identifier, patron-driven acquisition (PDA), mobile library.

\begin{abstract}
Since the traditional libraries can hardly meet the daily demands of the modern students, this paper proceeds from the concept of mobile library, and bases on the patron-driven acquisition (PDA) mode to put forward a plan to optimize the allocation of electronic and papery resources through techniques like digital objects identifier (DOI). The library of Southeast University is adopted as a case to prove the feasibility and promotion value of PDA theory from the perspective of pre-stage investigation and survey, introduction of technical routes, website design and trial operation results. Based on the theory, this paper explores the realization of the "Two-in-One" system featuring the combination of library's electronic and papery resources, and the promotion of the building of new-type libraries.
\end{abstract}

\section{Introduction}

Currently, Chinese society has entered the micro-era. The information dissemination modes have undergone diversified changes. University and college students, the service target of university and college libraries, are the major information force and loyal users of the micro-era. Smartphone facilitate university students' access to information. The development of various APP and functions subconsciously influence people's life status. Against the backdrop, scholars have conducted an in-depth exploration of library management modes, developed the concept of "mobile library," and put forward patron-driven acquisition (PDA) mode, thus laying a solid theoretical foundation.

Based on the advanced library management ideas [1-2], this paper puts forward the "Two-in-One" system library management mode featuring the combination of papery and electronic resources. Southeast University is adopted as a case. The concept of "mobile library" is applied to the library building of Southeast University. The PDA resource base building is employed to optimize the resource structure of the library of Southeast University, and prove that PDA is a new-type three-dimensional library management model keeping up with the era development. At the same time, Southwest University is committed to the employment of modern innovation techniques, the improvement of library service modes, the stimulation of the reading passion of students and teachers and the increase of the library resource utilization rate, which makes Southwest University a perfect case for the study on the service modes of mobile library.

\section{Research status and theoretical basis}

Mobile library. Currently, mobile library has become a hot topic in library research. The research into mobile library is mainly conducted from three perspectives, namely service modes, object elements, literature review and evaluation. The research into the service modes mainly includes the research into short message service, mobile network service and APP service. Among them, APP is a mobile value-added service, which integrates the APP techniques of QR (quick response) code, RSS (really simple syndication), LBS (location-based service) and so on. At present, the qualitative research dominates in this field. The empirical research focusing on analyzing users' demands, attitudes and suggestions is insufficient. [5] 
Some scholars have studied the APP services, including QR, RSS and LBS, respectively. In terms of QR, Walsh [6] introduced the project of University of Huddersfield to employ QR code to convey scenario-related information to users. DU Zhixin [7] et al. explored the application of QR code in mobile library and evaluated its efficacy. Massis, Semenz et al. [8] also studied the application of QR code in library. Chen [9] et al. put forward a novel smart mobile library recommendation system. Through the system, users can enjoy the path navigation service and obtain the information about the nearby libraries, which is beneficial for the readers' quick search of target learning materials.

QR Code (Digital objects identifier). QR code is in the shape of a square and features two colors, the black and the white. In three out of the four corners of the square are imprinted with a square pattern resembling the Chinese character “回.” The three patterns can help with decoding and software positioning. Users can scan the QR code from any direction to correctly read the information instead of targeting at it.

Compared with the previous barcodes, QR cord can store richer information, including text, URL address and other types of data encryption. Apart from standard QR code, there is a micro-QR code format, which is a miniature version of standard QR code. It is specially designed for the handling of large-scale scanning. Micro-QR code has various standards. It can store 35 characters at most.

QR code has found wide applications in digital libraries, including:

1) Library management.

Store the relevant information of books, such as authors, into the QR code, and then print the QR code to paste it on books and journals to realize the off-line use of data and bring convenience to readers. [11]

2) Connection between papery resources and electronic resources.

We can make pictures, videos, audios and other hyperlinks related to the papery resources into the QE code. The QR code can serve as a medium to connect the mobile devices and the papery resources. In this way, readers can have easy access to media resources related to the physical books, and experience the charm of mobile-end media while browsing through the printing books. The mobile digital library experience is brand-new to readers. [12]

3) Distance learning and education.

The retrieval and use methods of the current electronic resources in university and college libraries are not convenient, thus resulting in low use frequency. However, if the links and relevant information of electronic resources are stored in the QR code, students can download the required electronic resources at any place and any time, which can facilitate students' independent distance learning to a large extent. [13]

Patron-driven acquisition.Patron-driven acquisition (PDA) [14-15] is a literature resource building model featuring readers' decision-making. In other words, readers' reading demands are quantized into certain index. Based on the index, libraries purchase literatures. Originated from the traditional cross-library interlending services, PDA aims at promoting and supplementing the papery resources collection building. Now, it refers more to a new resource building model based on the readers' practical browsing and reading situation and about whether the acquisition index of certain literature is triggered by certain standard or parameter.

\section{“Two-in-One” system of library’s electronic and papery resources}

Status survey and analysis of libraries.First, a survey was conducted about the reading habits of some students in Southeast University, and their opinions about the book borrowing mode and book resources. At the same time, the author searched and collected the borrowing and utilization rate of various books during a period of time. The questionnaire survey showed that the utilization rate of students about the library resources is low and that most are not in use. The materials and books for their daily study do not come from libraries, but are electronic resources (such as textbooks, answers to exercises and previous exam paper) issued by upperclassmen or teachers. 
Others are textbooks and reference materials purchased by students themselves. The library data suggested that the students' utilization rate of library's electronic resources is far lower than the use rate of papery resources. The utilization rate of books related to advanced math is high. Other resources are not in use for a long time. The above survey reflected two problems. First, students do not have an easy access to electronic resources. Second, the library's resource allocation is not reasonable, or in other words, the library fails to fully meet students' demands.Through the above analysis, the root of the problems is that the library has not yet realized the overwhelming advantages of electronic resources over papery resources. Besides, the library fails to give full consideration of users' demand tendency and the rapid information update in the current society in terms of its library management mode and resource base building. Based on the above analysis, the author puts forward the following countermeasures.

Countermeasures. Based on the analysis results of questionnaires, this paper puts forward corresponding countermeasures so as to provide better library resource services for students and teachers.1) In terms of electronic resources, the referral information system shall be simplified. The digital identifiers and other methods shall serve as a bridge to connect papery and electronic resources to enable users to have easy access to electronic resources at any place and any time.2) In terms of literature resource construction, students' daily learning demands and specialized courses shall be studied to build a demand-based resource base. The demand-base resource base shall be regularly updated to adapt to changes in students' demands. 3) Resources can be issued through the online platforms. In other words, the advantages of electronic resources shall be fully utilized to update and simplify the resource base for easy operation. [16]

Solution plans. 1. Collection of journal information and QR code making. In total, 113 different journals and magazines published at different dates were chosen from the library of Southeast University, of which 78 are computer books, and 35 are mathematic books. In view of the rapid update of journals, the author only collected a brief introduction of journals [17-18], such as authors, ISSN, publishing houses, etc., and compiled them into the QR code to achieve the combination of papery and electronic resources. 2. Collection of data about specialized courses and QR code making. Proceeding from the PDA model, some schools of Southeast University were chosen to establish a resource base featuring students' demands for resources related to specialized courses. The resource base includes electronic resources such as textbooks for some courses, answers to the after-class exercises, and other relevant study materials. In terms of every book and material, its electronic text resource link is compiled into the QR code (including the physical and electronic version) to enable students to use electronic resources at any time and any place.

\section{Realization of the "Two-in-One” system of library's papery and electronic resources}

Demand analysis report based on the user survey. According to the previous user survey, some online functional modules were established, including BBS, learning resources module, user upload system, intelligent research, APP port, intelligent recommendation, QR code column, feedback mechanism, etc. 


\section{General website design and structure analysis.}

\begin{tabular}{|c|c|c|c|}
\hline \multicolumn{4}{|c|}{ Open Your World } \\
\hline \multirow{2}{*}{$\begin{array}{l}\text { User permission } \\
\text { management }\end{array}$} & Students & \multicolumn{2}{|c|}{$\begin{array}{l}\text { Registration, log-on, intelligence recommendation, search } \\
\text { history, BBS and uploaded resources }\end{array}$} \\
\hline & Administrators & \multicolumn{2}{|c|}{$\begin{array}{l}\text { Log-on, reference to the added or modified students’ data } \\
\text { and their book borrowing information (including new } \\
\text { acquisitions, QR code, etc.), log-on and management } \\
\text { network disk. }\end{array}$} \\
\hline \multirow{4}{*}{$\begin{array}{c}\text { Book } \\
\text { information } \\
\text { management }\end{array}$} & \multirow[t]{3}{*}{ Students } & \multirow[t]{3}{*}{ Book search } & Accurate search \\
\hline & & & Classified search \\
\hline & & & Vague search \\
\hline & Administrators & \multicolumn{2}{|c|}{$\begin{array}{l}\text { Reference to the added or modified materials (including } \\
\text { cover picture, brief introduction QR code, etc.), the number, } \\
\text { variety and borrowing quantity of books, and other relevant } \\
\text { information. }\end{array}$} \\
\hline $\begin{array}{c}\text { BBS } \\
\text { management }\end{array}$ & Students & \multicolumn{2}{|c|}{ Post and reference to comments about relevant books. } \\
\hline \multirow{2}{*}{$\begin{array}{l}\text { Network disk } \\
\text { management }\end{array}$} & Students & \multicolumn{2}{|r|}{ Resource upload } \\
\hline & Administrators & \multicolumn{2}{|c|}{$\begin{array}{l}\text { Management of network disc resources, increase and } \\
\text { assorting of network disc resources on a regular basis. }\end{array}$} \\
\hline
\end{tabular}

Detailed website design and project implementation.1. Front-end realization of website. The target users of the website are students studying in Southeast University. The theme is the library electronic resources. Thus, the website style is positioned to be simple and elegant. The refreshing warm tone gives users a comfortable and quiet feeling so as to create favorable user experience. Bookstrap, CSS, Html, JavaScript and other relevant techniques are adopted. 2. Back-end technical realization. (1) Website techniques: Oracle database, back-end technical framework, Spring-MVC, Spring and Mybatis.(2) Connection with students' information database system: Under the guidance of the librarians, the website database is connected with the students' information database system to realize the goal of serving students in Southeast University.

The realization of “Two-in-One” System of library's papery and electronic resources. The specialized website called "Open Your World" created in this paper is a resource issuance platform, which contains information for the making of journals, and the establishment of an electronic resource base oriented towards teachers and students in Southeast University. In terms of journal modules, the website will modify and update the journal information regularly concerning the characteristics of journals. In the journal screen, the hyperlink to the electronic version and the QR code storing relevant information are provided for the convenience of student to refer to the required literature. In terms of the electronic resource base, in order to meet the demands of students and teachers in Southeast University, resources related to advanced math and other optional courses or other popular majors are basically summarized and assorted so as to solve the status quo of short supply of resources for these courses. In order to maintain the vitality and update speed of the website, the online BBS and the user upload mechanism are set up to enable teachers and students to participate in or even dominate the construction of the resource base. In this way, it is easier for 
the resource base to be expanded and updated. At the same time, the copyright of all the resources collected in this paper belongs to Southeast University. Therefore, the author directly connects users with the campus card to prevent the leakage of the resources.

\section{Summary and outlook}

According to users' experience reports and the website utilization data, the trial operation of the website shows favorable results in Southeast University. Through the website, the journal information can be immediately updated to help students to quickly find their target information. Besides, the students-oriented resource base can fully meet students' daily demands, which effectively solves the problem of low utilization rate and inconvenient use of the university library. Besides, users' utilization frequency of the website keeps on increasing rapidly, which suggests that the website can make up the gap of the current library. BBS, user upload mechanism and other feedback systems can help update and improve network resources to ensure long-term operability of the website.The establishment of the literature resource base featuring the combination of electronic and papery resources can effectively improve the low utilization rate of libraries, and the structure disequilibrium of book collection. Due to the sharing nature of electronic resources, the problem of shortage of copies of some popular resources resulted from centralized borrowing is solved. Moreover, the electronic resources can be easily updated, and consume fewer human resources and material resources, so it can reduce the management and update cost to some extent. To sum up, the PDA literature source base establishment mode featuring the combination of papery and electronic resources can create a brand-new library management and operation mode, better meet students' demands, and are more economic and convenient, thus they can be widely applied in libraries of universities and colleges nationwide, and municipal libraries as well.

\section{References}

[1] WANG Hongjian. Design and realization of library management system[D]. Chengdu: University of Electronic Science and Technology of China, 2013.

[2] GUAN Xuelun. Analysis and design of library management system for universities and colleges[D]. Beijing: Beijing University of Posts and Telecommunications, 2012.

[3] LIU Hua. The revelation of PDA practices in American university and college practices on China[J]. Journal of Academic Libraries, 2012(01).

[4] ZHANG Shuqin.A tool to manage digital publishing: Digital Objects Identifier (DOI) System[J]. Publishing Research, 2007(04)

[5] ZHANG Yanlei. Analysis of the application of QR Code in digital libraries[J]. Journal of Modern Information, 2007(10).

[6] Walsh A. QR Codes - using mobile phones to deliver library instruction and help at the point of need [J]. Journal of information literacy, 2010,4(1):55-64.

[7] DU Zhixin \& KANG Qi. Application of QR Code in mobile library marketing[J]. Library Journal, 2007.

[8] Massis B E. QR Codes in the library [J]. New Library World. 2011,112(9-10):466-469.

[9] Yang B, Chen J. Building Secure Tame-like Multivariate Public Key Cryptosystems-the New TTS[A].Information Security and Privacy:10th Australasian Conference-ACISP.2005[C].LNCS,Springer.2005.3574:518-531.

[10] Nor Irvoni Mohd. Ishar \& Mohd. Saidfudin Masodi. Students' perception towards quality library service using Rasch measurement model. Innovation Management and Technology Research 
(ICIMTR), International Conference on Innovation, Management \& Technology Research, 2012: 668-672.

[11] Kiran,K. \& Diljit, S. Modelling web-based library service quality[J]. Library Information Science Research, 34 (3), 2012: 184-196.

[12] Kulthida Tuamsuk, Kanyarat Kwiecien, Jutharat Sarawanawong. A university library management model for students' learning support[J]. The International Information \& Library Review, 2013, 45(3-4).

[13] Atk inson R. Managing traditional materials in an online environment: some definitions and distinctions for a future collection management[J]. Library resources \& technical services.

[14] LIU Hua. Patron-driven literature resource building-a study on the PDS in American academic libraries[J]. Library and Information Service, 2012(05).

[15] Polanka,S, Off the shelf Patron-driven acquisition[J]. Booklist, 2009(1):121.

[16] Esposito J.J. Patron-driven Acquisitions: History and Best Practices[M]. Learned Publishing. 2012,25(2):155-156.

[17] Presenters S.F., G.W. Presenters and L.E. Recorder. Managing E-book Acquisition: The Coordination of"P”and“E”Publication Dates[M]. The Serials Librarian, 2012(62):200 -205. 